Rambam Medical Center, Haifa 31096, Israel

Department of Internal Medicine D

T Hayek

JG Brook

Department of

Radiology

A Engel

A Eyal

Correspondence to Prof JG Brook

Accepted 18 November 1996

\section{Abdominal retroperitoneal lymphadenopathy in an elderly man}

\author{
T Hayek, A Engel, A Eyal, JG Brook
}

A previously healthy 69-year-old man was referred to our department. He had a three-month history of deterioration of bilateral ankle and leg oedema and had recently undergone an abdominal ultrasound and computed tomography (CT) scan in another hospital. An abdominal aortic aneurysm was detected and enlarged retroperitoneal lymph nodes were suspected. On admission, the only abnormality on physical examination was bilateral ankle and leg oedema extending to mid-calf. There was no peripheral lymphadenopathy, hepatosplenomegaly or ascites. A repeat abdominal CT scan was performed.

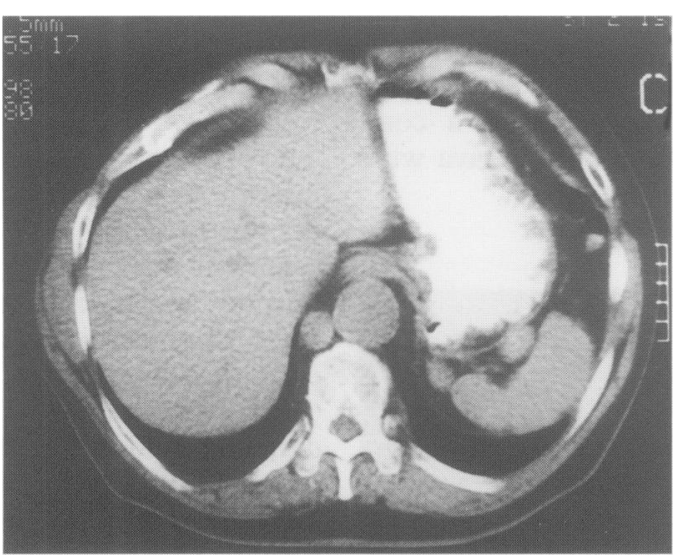

\section{Questions}

1 What is the most likely cause of the 'retroperitoneal lymphadenopathy' in this patient? 2 What other diagnosis should be considered?

Figure 1 Abdominal CT scan 


\section{Answers}

QUESTION 1

Suprarenal interruption of inferior vena cava with azygous continuation.

Based on the initial interpretation of the abdominal CT, our aim was to exclude the two most common causes of retroperitoneal lymphadenopathy - lymphoma and metastatic disease. Liver scan, liver biopsy, bone marrow aspiration and bone marrow biopsy were all normal. The CT scan showed an enlarged azygous vein. This was interpreted as the azygous continuation of the inferior vena cava. The CT also showed interruption of the inferior vena cava with wide collaterals resembling 'enlarged lymph nodes'. Accessory spleens were also demonstrated.

A similar picture was seen on review of the previous CT scan. Inferior vena cavography (figure 2) confirmed the diagnosis and demonstrated a conical obstruction of the inferior vena cava in the suprarenal area, with marked collateralisation through the azygous and hemiazygous systems. The diagnosis was a congenital anomaly of the inferior vena cava with accessory spleens.

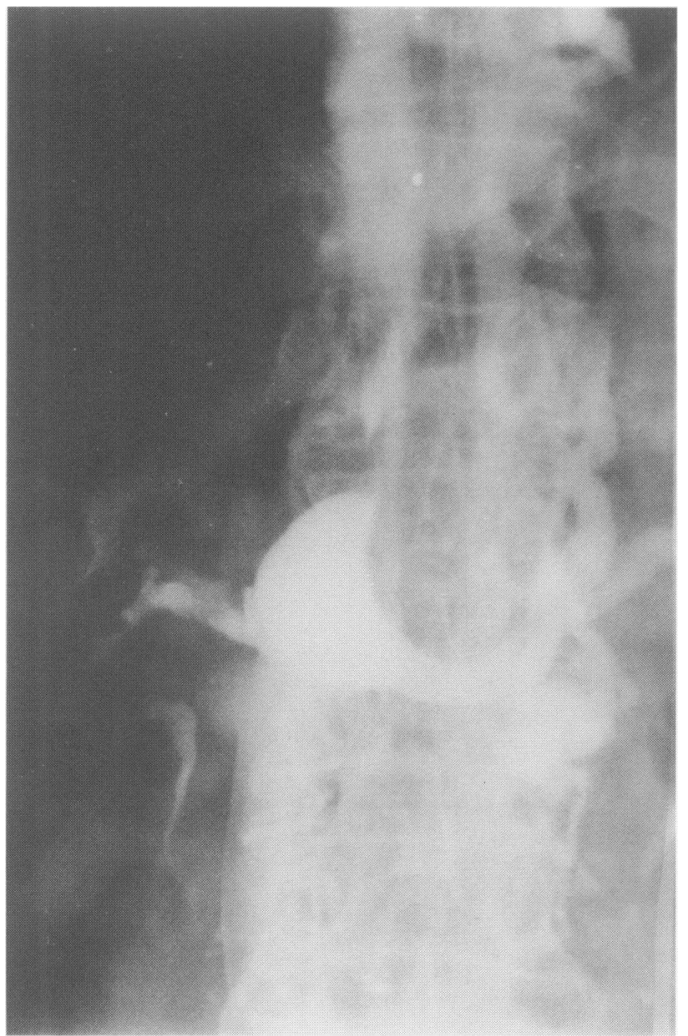

Figure 2 Inferior vena cavography

1 Huberman R, Gomes AS. Membranous obstruction of the

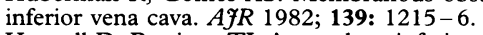

2 Haswell D, Berrigan TJ. Anomalous inferior vena cava with accessory hemiazygous continuation. Radiology 1976; 119. $51-4$.

3 O'Reilly RJ, Grollman JH. The lateral chest film as an unreliable indicator of azygous continuation of the inferior vena cava. Circulation 1976; 53: 891-5.

\section{Learning points}

- suprarenal interruption of inferior vena cava with azygous (hemi-azygous) continuation may mimic abdominal retroperitoneal lymphadenopathy

- diagnosis of this anomaly is vital to prevent unnecessary investigation and is thus not merely of academic interest

\section{QUESTION 2}

The azygous continuation may mimic a tracheobronchial angle mass, a right paravertebral mass, or, as in this case, enlarged retroperitoneal lymph nodes, but a careful review of the CT scan and the inferior vena cavography confirmed the diagnosis of suprarenal interruption of inferior vena cava with azygous continuation.

\section{Discussion}

The embryological development of the normal inferior vena cava azygous system is welldocumented. If the hepatic and pre-renal segments of the inferior vena cava fail to unite properly, persistence of the mid-portion of the right supracardinal vein leads to azygous continuation. ${ }^{1}$

The abdominal CT scan (figure 1) clearly demonstrated the pathognomonic features of this anomaly. At the level of the renal veins, the inferior vena cava was not identified. The azygous and hemi-azygous veins were enlarged (because they carried most of the returning blood from the abdomen and lower extremities), and initially misinterpreted as enlarged retroperitoneal lymph nodes.

The azygous continuation may mimic a tracheobronchial angle mass, a right paravertebral mass, or, as in this case, enlarged retroperitoneal lymph nodes. Diagnosis of this anomaly is important to prevent unnecessary investigation (such as exploratory laparotomy) and is therefore not merely of academic interest. $^{2-5}$ We suggest that every case of enlarged retroperitoneal lymph nodes found on CT scan must be carefully reviewed and this anomaly excluded.

\section{Final diagnosis}

Suprarenal interruption of inferior vena cava with azygous continuation.

Keywords: lymphadenopathy, inferior vena cava

4 Heller R, Dorst J, Rowe R. A useful sign in the recognition of azygous continuation of the inferior vena cava. Radiology 1971; 101: $519-22$

5 Berdon W, Baker D. Plain film findings in azygous continuation of the inferior vena cava. Radiology 1968; 104: $452-7$. 